\title{
The rice pathogen-related protein 10 (JIOsPR10) is induced by abiotic and biotic stresses and exhibits ribonuclease activity
}

\author{
Sun Tae Kim · Seok Yu • Young Hyun Kang • \\ Sang Gon Kim · Jae-Yean Kim · Sun-Hyung Kim • \\ Kyu Young Kang
}

Published online: 3 September 2008

(C) Springer-Verlag 2008

Erratum to: Plant Cell Rep (2008) 27:593-603

DOI 10.1007/s00299-007-0485-6

Unfortunately, the presentation of Fig. 6 was wrong.

The correct Fig. 6 is given below.

The online version of the original article can be found under doi:10.1007/s00299-007-0485-6.

S. T. Kim · J.-Y. Kim · K. Y. Kang $(\bowtie)$

Environmental Biotechnology National Core Research Center,

Gyeongsang National University, Jinju 660-701, Korea

e-mail: kykang@gnu.ac.kr

S. Yu $\cdot$ J.-Y. Kim $\cdot$ K. Y. Kang

Plant Molecular Biology and Biotechnology Research Center,

Gyeongsang National University, Jinju 660-701, Korea

Y. H. Kang · S. G. Kim · J.-Y. Kim · K. Y. Kang

Division of Applied Life Science (BK21 Program),

Gyeongsang National University, Jinju 660-701, Korea

S.-H. Kim

Department of Environmental Horticulture,

University of Seoul, Seoul 130-743, Korea 

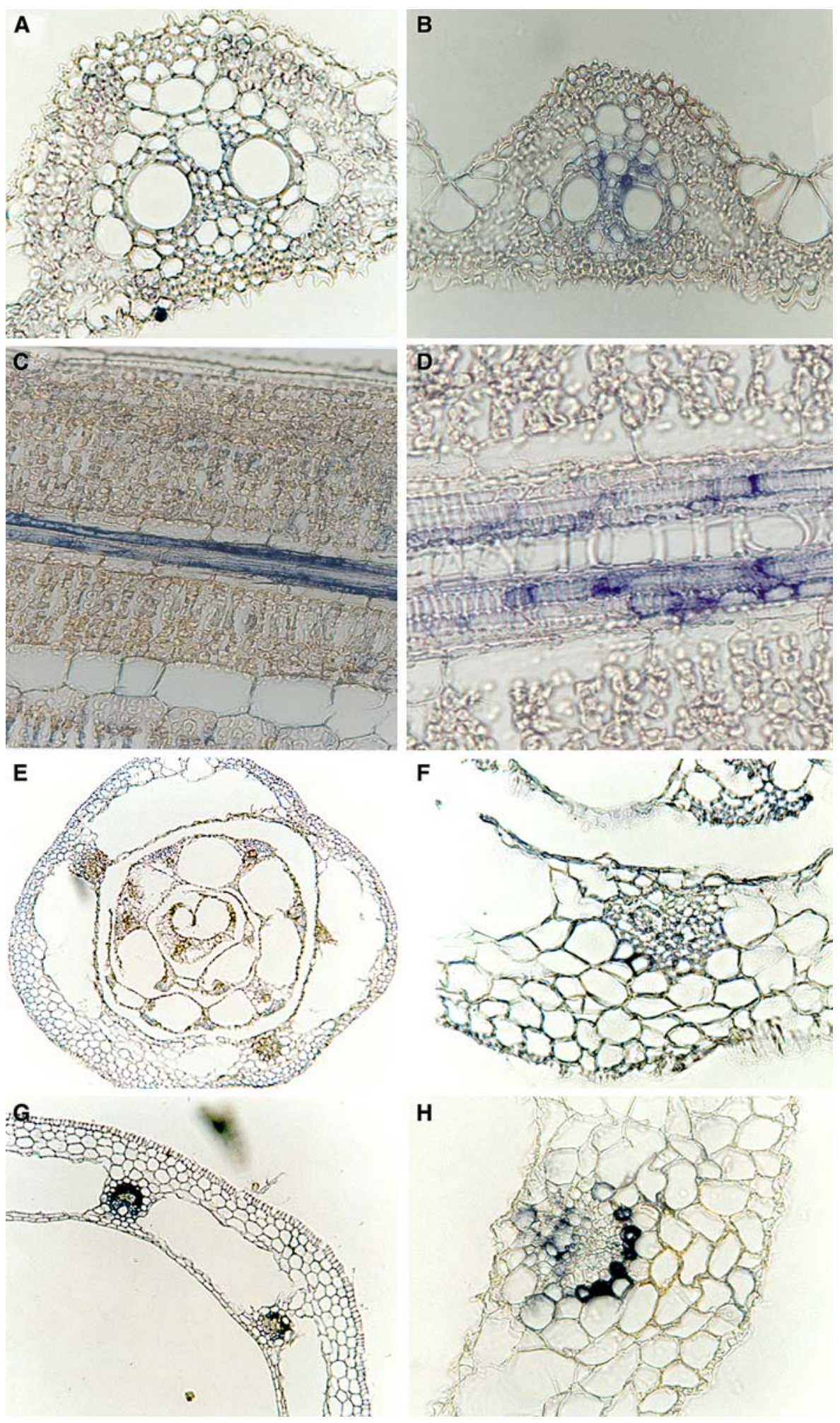

Fig. 6 Immunolocalization of JIOsPR10 proteins during leaf and cloeoptiles senescence. For immunohistochemical analysis, sections from senescent leaf and coleptiles obtained with a microtome were incubated with purified JIOsPR10 antibody (dilution 1:100). Transverse (a and b) and longitudinal (c and d) sections of the senescent leaf and all transverse $(\mathbf{e}, \mathbf{f}, \mathbf{g}$, and $\mathbf{h})$ sections of the coleoptiles were

incubated with anti-JIOsPR10. Tissues were treated with preserum as a negative control (a, e, and f). The sections were incubated with alkaline phosphatase-conjugated anti-rabbit IgG antibody (dilution 1:300) for $1 \mathrm{~h}$ and visualized after the addition of NBT/BCIP solution for $20 \mathrm{~min}$ 